\title{
Internet of Things Application in Monitoring Sick Building Syndrome
}

\author{
Keshihakumar Kalaithasan', N. A. M. Radzi' ${ }^{2}$ H. Z. Abidin ${ }^{3}$ \\ ${ }^{1,2}$ Electronics Communication Department, College of Engineering, Institute Of Informatics And Computing In Energy, \\ Universiti Tenaga Nasional, Jalan Ikram-Uniten, 43000 Kajang, Selangor, Malaysia \\ ${ }^{3}$ Faculty of Electrical Engineering, Universiti Teknologi MARA, 40450 Shah Alam, Selangor, Malaysia
}

\begin{tabular}{l} 
Article Info \\
\hline Article history: \\
Received May 19, 2018 \\
Revised Jul 20, 2018 \\
Accepted Aug 3, 2018 \\
\hline
\end{tabular}

\section{Keywords:}

FavorIot Internet of things

Raspberry pi

Sensors

Sick building syndrome

\begin{abstract}
Sick Building Syndrome (SBS) is a health condition whereby a patient is presented with either vague temporary symptoms such as fatigue, aches and sensitivity to odour or more significant temporary symptoms such as itchy eyes, skin rashes and nasal allergy when they are in a building. Numerous factors have been associated with SBS, but the lack of an accurate diagnosis for these symptoms make treatment more difficult, as risk of treating the patient with wrong diagnosis is relative when the cause root is not known. Thus, taking a preventive approach is a more viable solution to the problem. In this paper, a simple, mobile and cost efficient Internet of Things (IoT) based SBS system is proposed. The system is built using Raspberry Pi minicomputer that would then be integrated with an IoT middleware. The middleware would enable the user to monitor parameters that are to be tested; which are temperature, humidity, light, sound and dust. Three IoT middleware are used to evaluate which one works best for the SBS system proposed. The combination of recorded sensor data would then be used to determine whether or not the building is causing SBS to the occupant. The studies show that FavorIoT platform is the most suitable IoT platform to be used with the SBS system and the system has successfully identified whether or not a building is causing SBS.
\end{abstract}

Copyright $\odot 2018$ Institute of Advanced Engineering and Science. All rights reserved.

\section{Corresponding Author:}

Keshihakumar Kalaithasan,

Electronics Communication Department, College of Engineering,

Institute Of Informatics And Computing In Energy, Universiti Tenaga Nasional,

Jalan Ikram-Uniten, 43000 Kajang, Selangor, Malaysia.

Email: asyikin@uniten.edu.my

\section{INTRODUCTION}

Sick Building Syndrome (SBS) is a health condition whereby a patient is presented with temporary symptoms in which they subside after the patient is out of a building. Even if the symptoms are more severe, recovery periods are longer but the symptoms do improve over time [1]. Generally, the symptoms are categorized into five categories, which are mucus membrane irritation, neuropsychiatric disturbances, skin disorders, asthma-like symptoms and unpleasant odour and taste sensation. However every researchers have different proposals on the factors that are causing SBS.

Passsarelli [2] identified the causing factors of SBS to be inadequate ventilation/poor indoor air quality, volatile organic compounds (VOC), internal and external sources of pollution, temperature, humidity, noise, inadequate lighting and psychological factors. On the other hand, according to Sumedha [3], chemical contaminants, biological contaminants, inadequate ventilation, electromagnetic radiation, psychological factors, poor lighting or absence of natural light, bad acoustics, poor ergonomics, humidity and temperature are the factors that cause SBS. According to Thorn [4], symptoms relating to SBS are influenced by the interactions between biomedical and psychosocial issues. He identified parameters such as mechanical 
ventilation, VOC, dust, noise, indoor temperature, psychosocial discontent, wall-to-wall carpets and textiles, illumination, formaldehyde, work with photocopying, gender, tobacco smoking and topic disease history to be the caused of SBS.

As each researchers identify different causing factors of SBS, it makes it difficult to diagnose the symptoms. The lack of an accurate diagnosis for these symptoms make treatment more difficult, as risk of treating the patient with the wrong diagnosis is relative when the cause root is not known. Thus, taking a preventive approach is a more viable solution to the problem.

In this paper, a simple, mobile and cost efficient Internet of Things (IoT) based SBS system is proposed. The system is built using Raspberry Pi minicomputer that would then be integrated with an IoT middleware. The middleware would enable the user to monitor parameters that are to be tested. Three IoT middleware are used to evaluate which one works best for the SBS system proposed. The combination of recorded sensor data would then be used to determine whether or not the building is causing SBS to the occupant.

The rest of the paper is organized as follows. Section 2 discusses on the proposed SBS system, Section 3 on the IoT middleware, Setion 4 is on results and discussions and Section 5 concludes the findings.

\section{PROPOSED SBS SYSTEM}

The SBS system is made of a set of sensors with a processing module. Raspberry Pi 3 Model B has been chosen as the brain of the SBS system. It is able to read flash drives with the existing Universal Serial Bus port on board. Besides, the Raspberry Pi has a built in Wi-Fi module that allows it to connect to a network, making it suitable choice for IoT based products.

There are some SBS parameters that are not measurable such as psychological factors which is difficult to be monitored [5]. Thus, for the scope of this paper, non-measurable parameters would not be taken into account as part of the monitoring and detection system.For proof of concept, five crucial parameters are chosen to provide an analysis of the monitoring and detection of SBS. The parameters are temperature, humidity, particulates, sound and light.

As for the chosen parameters that are related to the the Heating Ventilation and Air Conditioning (HVAC) system, noting that air flow is also quite significant to this subject matter, yet it is not chosen because it is related to temperature and the humidity. Meaning, if there is a significant rise or drop in temperature or humidity, it would be safe to conclude that the air flow is the cause [6]. Adding to that, choosing between particulates in the air and the air flow, the concentration of air particulates outweighs the content of air in the in building as particulates can cause more harm.

There are many sensors in the market compatible with Raspberry Pi. However, its accuracy, cost and functionalities have to be considered. DHT 22 is used to measure the temperature and humidity with accuracy of $\pm 2 \%$ for humidity and $\pm 0.5^{\circ} \mathrm{C}$ temperature. The optimum working ranges are $0-100 \% \mathrm{RH},-40$ $80^{\circ} \mathrm{C}$.

Sharp's GP2Y1010AU0F Optical Dust Sensor is used to measure the content of particles in a cubic meter of air as it is sensitive to fine airborne particles. On the other hand, Flying Fish Light Sensor is chosen to measure the light intensity from the environment within 0-20000 lux. It is based on photodiode which is more responsive towards light. KY-038 is used to measure the noise level of the surrounding in the frequency range: 100-10000 Hz.Finally, using Raspberry $\mathrm{Pi}$ as the processing unit would require an analog to digital converter as, the GPIO pins on the boards are all digital pin. Thus, the ADS1115 would be used for this concept. Taking into fact that, light and sound sensors measure the parameters in voltages, a wider bit conversion would allow the sensor data to be in a more reliable voltage range. Meaning that the use of the ADS1115 analog to digital converter would enable a greater range of sensitivity, hence a better sensor reading.

As for the software, using Python to measure, record, analyze and transfer the data would be the most suitable language to use, as it is compatible with the Raspberry Pi and it is also a language that is easily understood, making diagnostics simpler. The system works by first reading the data from sensors and upload them to FavorIoT platform. The SBS probability then will be calculated and uploaded back to the IoT platform.

According to the EPA and studies done by other researchers, the most optimal room temperature is between $20-25^{\circ} \mathrm{C}$ [7]. Increase in temperature beyond $25^{\circ} \mathrm{C}$ is related to the increase in number of occupants who complain of headaches. As for the humidity, condition whereby the humidity is beyond the range of $35-$ $65 \% \mathrm{RH}$, could cause serious health risks if the condition is prolonged [8]. Dust density, is also an important parameter where $100 \mathrm{mg} / \mathrm{m}^{3}$ of dust density could be very dangerous for the lungs and could even cause respiratory failure in occupants with respiratory problems [9]. The optimal lighting or illuminance in a room or building is to be within the range of 500 to 750lux [10]. High noise levels on the other hand, are said to 
cause temporary or even permanent hearing impairment. Besides, noise is also quite highly related to many psychological disorders and as well as stress. Thus, the noise levels should be maintaining within the range of 35 to 80 decibels [11].

\section{IOT MIDDLEWARE}

Device testing was performed with three different types of IoT platforms for DHT 22 and the optical dust sensor. The initial design was a simple one with the sensors connected to the Raspberry Pi. However, the implementation of the sensors raised a few issues that required a redesign in order for the sensors to function as intended. These issues were mainly regarding the dust sensor as well as the light and sound sensor. The dust sensor was not entirely compatible with the Raspberry Pi as it requires a Pulse Width Modulation (PWM) module, which the Raspberry Pi did not have on board. Due to cost constraints, the best solution for the time being was to use an Arduino that was already available. The Arduino has a PWM pins that would work well with the dust sensor in reading the data from the sensor.

Besides issues with the dust sensor, the light and sound sensors also had issues intergrating with the Raspberry Pi. These sensors are based on the LM-393 comparator, able to give out either an analogue or digital signal. However, the GPIO pins on the Raspberry Pi are all digital pins, meaning that analog data or signal from the sensors would not be recognized or detected. Thus, an analog to digital converter (ADC) is needed, more accurately the ADS1115, 16bit ADC.

Figure 1 shows the wiring diagram to integrate the sensors with the Raspberry Pi and Arduino respectively. The Arduino is connected to the Raspberry Pi via serial cable, and the data from the Arduino is read by the Raspberry Pi using the serial library on board the minicomputer.

There are many IoT platforms that are widely available on the internet, these platforms can be of open source or even a paid service. In order to determine the most suitable platform for this project, three platforms are chosen and tested with the Raspberry Pi. These platforms are ThingSpeak, Ubidots and FavorIoT.

\subsection{ThingSpeak}

This platform is known to be an IoT analytics platform service that allows the user to aggregate, visualize and analyze live data streams in the cloud. MATLAB codes can be executed with this platform to process data as it comes in. ThingSpeak is often used for prototyping and proof of concept IoT systems that require analytics. As observed in Figure 2 a for temperature sensor, there is a 0.1 degree drop in temperature according to the graph that is presented, with very minimal fluctuations in temperature which is highly unlikely. This is because the platform only recognizes three significant figures for the graphical representation. This makes it less sensitive, and minute variations in the temperature are not observable in the graph. This is why the trend seems pretty constant throughout the test carried out.

As for the humidity graph in Figure $2 b$, similar to the temperature graph presented, the sensitivity of the data is quite low. However, due to a significant rise and drop of humidity, the fluctuations are still observable here. A decrease in humidity is observed, starting of at $80.5 \% \mathrm{RH}$ and $79.8 \% \mathrm{RH}$ at the end of the test, a drop of $0.7 \% \mathrm{RH}$ or $0.87 \%$. The humidity fluctuates within a high of $80.5 \% \mathrm{RH}$ and a low of $79.7 \% \mathrm{RH}$.

The data presentation in ThingSpeak is observed to be very similar to the data presented in FavorIoT. The dust density observed in Figure $2 \mathrm{c}$ remains constant around $0.02 \mathrm{mg} / \mathrm{m}^{3}$, with a few fluctuations. These fluctuations would most because by the change in air flow.

\subsection{Ubidots}

Ubidots was first born as an engineering services firm, specializing in hardware and software development for IoT projects in Latin America. The first line graph on top of Figure 3a shows the exact changes in temperature for the tested period. The second line graph is the continuous average graph that shows the average temperature values of that period of time. Similar to ThingSpeak, the graph presented here are not detailed, which affects the quality of the analysis. In this case, the graph only recognizes whole numbers, thus making it less sensitive towards the data. This is the reason that there are no fluctuations in temperature seen in the first 25 minutes, the temperature is observed to be constant at 30 degrees. A significant change in the data is only observed around $10: 35 \mathrm{pm}$, whereby the temperature rises a degree to 31 degrees.

The changes observed are more significant and are able to be observed in the graph from Figure $3 \mathrm{~b}$. The humidity within the tested period is said to be in the range of $76 \% \mathrm{RH}$ and $77 \% \mathrm{RH}$. An initial gradual increase is observed followed by a significant drop in humidity is observed. This again relates as to why the data or the graph presents such trend, which is solely due to the relationship between temperature and humidity, as discussed previously. The drop-in humidity is about the same time as the rise in temperature is observed. 

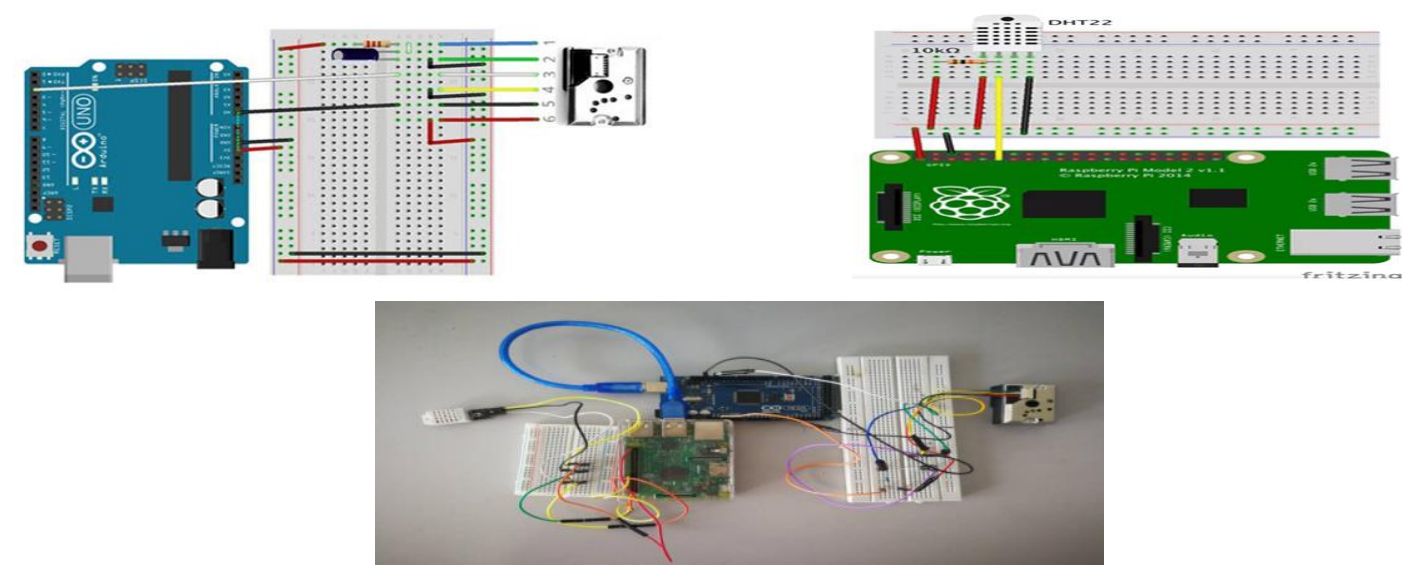

Figure 1. Prototype with the DHT22 and the optical dust sensor integrated
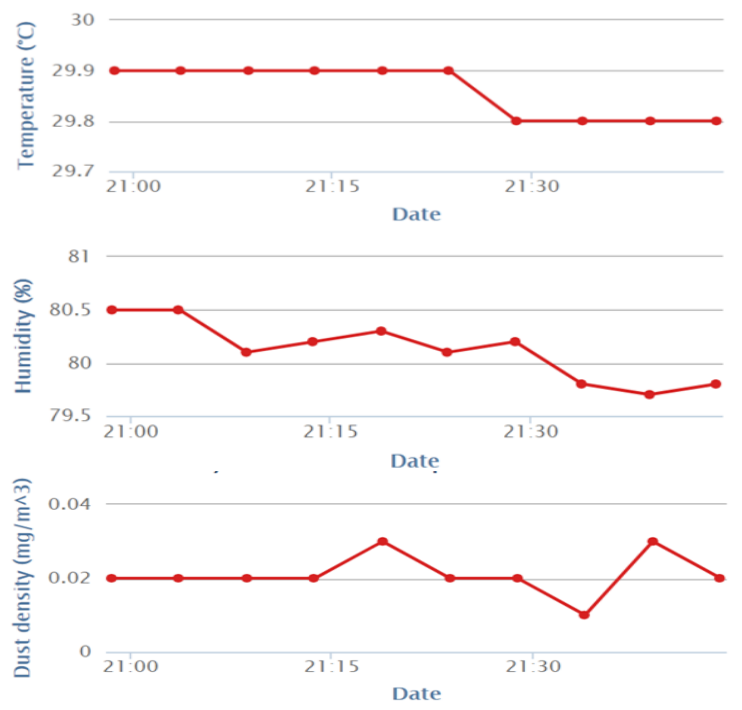

Figure 2. Recorded data from a) temperature, b) humidity and c) dust sensors in thingspeak

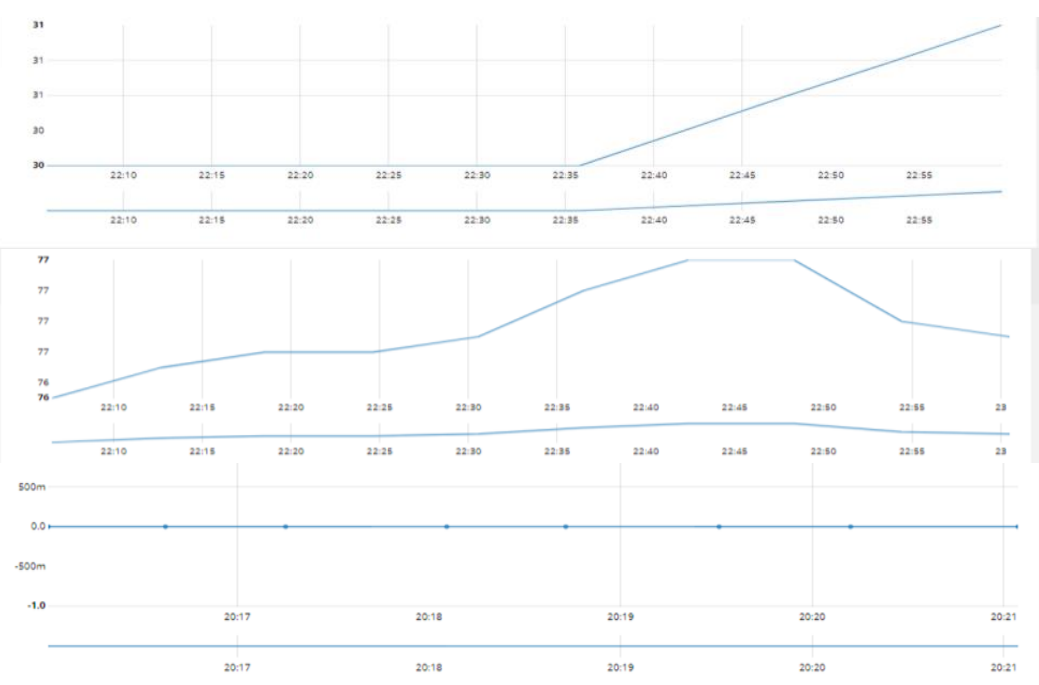

Figure 3. Recorded data from a) temperature, b) humidity and c) dust sensors in Ubidots 


\subsection{FavorIoT}

This platform is developed by a local group, led by Dr. Mazlan Abbas former CEO of RedTone telecommunications. FavorIoT is a middleware platform that is designed to be integrated or to provide IoT based services.

Temperature readings using FavorIoT is show in Figure 4a. At a glance, it is clear that there is an overall increase in temperature, an increase of 0.4 degree or an increase of $1.35 \%$ in about an hour. Also, it has a high of 30 degrees and a low of 29.5 degrees. There are fluctuations in the temperature, but referring to the values, these fluctuations are very minute. These fluctuations are expected, due to the tested location that has open windows and constant air flow.

A general decrease in the humidity is observed in Figure $4 \mathrm{~b}$, starting off at $77.5 \% \mathrm{RH}$ and at $74.9 \% \mathrm{RH}$ at the end of the test. That is a decrease of $2.6 \% \mathrm{RH}$ or $3.3 \%$ in about an hour. The fluctuations here are, not as significant as the temperature trend, a gradual average decrease is observed.

The dust sensor works by calculating the amount of dust present as dust particles flows through the opening in the sensor. The result is shown in Figure 4c. Thus, higher air flow will result in more dust particles flowing through the opening. Initially we observe the dust density constant at $0.02 \mathrm{mg} / \mathrm{m}^{3}$, then it rises to $0.03 \mathrm{mg} / \mathrm{m}^{3}$ and drops down to $0.01 \mathrm{mg} / \mathrm{m}^{3}$. Following that drop, the value returns back to 0.02 $\mathrm{mg} / \mathrm{m}^{3}$ and remains at that value for about 10 minutes before rising back to $0.03 \mathrm{mg} / \mathrm{m}^{3}$. This could be mainly caused by the variations in air flow within the room.

\subsection{IoT Platforms Study}

The comparison in Table 1 shows the important aspects that an IoT platform should have among the three chosen platforms. The aspects are the user interface, the delay involved, the platforms features, coding complexity and sensor integration, and as well as the service cost.

Based on the data and the comparisons made among the three chosen IoT platforms FavorIoT is chosen as the best IoT platform for this paper compared to the other two platforms.
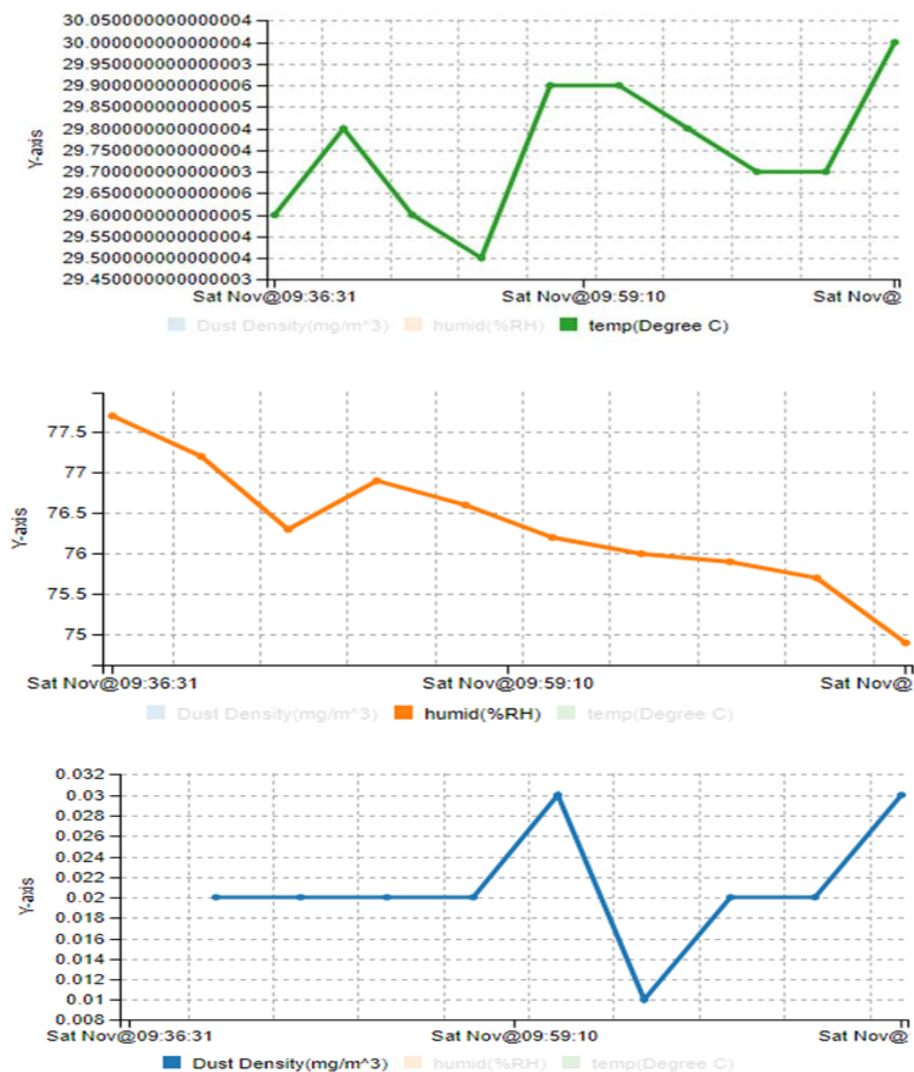

Figure 4. Recorded data from a) temperature, b) humidity and c) dust sensors in FavorIoT 
Table 1. Comparisons between ThingSpeak, Ubidots and FavorIoT

\begin{tabular}{|c|c|c|}
\hline $\begin{array}{l}\text { Aspects } \backslash \text { IoT } \\
\text { platform }\end{array}$ & ThingSpeak & FavorIoT \\
\hline $\begin{array}{l}\text { User interface and } \\
\text { Data presentation }\end{array}$ & Good & $\begin{array}{l}\text { UI heavy, good options of graphical Good } \\
\text { representation }\end{array}$ \\
\hline Delay involved & $\begin{array}{l}\text { Subjective to network speed, } \\
\text { allows simultaneous data upload } \\
\text { thus not significant delay. }\end{array}$ & $\begin{array}{l}\text { Subjective to network speed, Subjective to network speed, allows } \\
\text { significant delays are expected as simultaneous data upload thus not } \\
\text { each sensor has its own ID which is to significant delay. } \\
\text { be coded separately. }\end{array}$ \\
\hline $\begin{array}{l}\text { Coding } \\
\text { complexity }\end{array}$ & $\begin{array}{l}\text { Simple, basic coding knowledge } \\
\text { is sufficient. Not much coding } \\
\text { involved in order to upload the } \\
\text { data. }\end{array}$ & $\begin{array}{l}\text { Complex coding, the complexity Does not have a dedicated python } \\
\text { increases with more sensors, as more library, higher level of coding } \\
\text { bugs and network errors are observed, knowledge is required to understand } \\
\text { which has to be debugged. }\end{array}$ \\
\hline Features & $\begin{array}{l}\text { Library allows } \\
\text { simultaneous upload of data } \\
\text { from the related sensors, } \\
\text { thus lesser delay. } \\
\text { - Analytical tools are } \\
\text { available to perform } \\
\text { Analysis in greater depth. } \\
\text { Data can be exported into a } \\
\text {.CSV file for spreadsheet } \\
\text { representation. } \\
\text { Has a python library. }\end{array}$ & 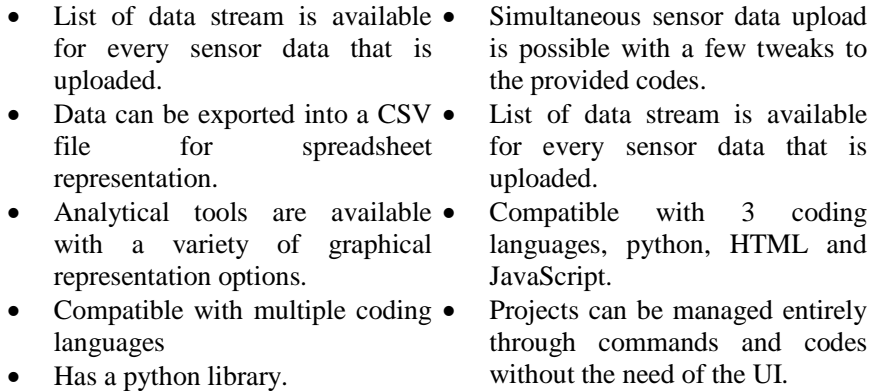 \\
\hline Cost of service & $\begin{array}{l}\text { Free service, with premium } \\
\text { additional features. }\end{array}$ & $\begin{array}{l}\text { Free service, with premium additional Free service for university, with } \\
\text { features. } \\
\text { premium additional features. }\end{array}$ \\
\hline
\end{tabular}

\section{RESULTS AND DISCUSSIONS}

Figure 5 and 6 show a simple block diagram and the connections used in integrating the sensors with the Raspberry Pi and IoT Middleware. The sensors are all placed in a box or container with a connected power brick. The box now by itself behaves as a multifunctional wireless sensor that is capable of uploading the sensor data to the IoT Middleware. The Arduino Mega as shown the in the figure is connected to the Raspberry Pi via the Universal Serial Bus Cable. The Arduino is preprogrammed via serial read to read the values from the dust sensor and upload them to the Raspberry Pi.

The tests were conducted at specific times to observe whether the external environment influences the indoor environment. Thus, tests were done in the evening and in the morning for a building with HVAC and without HVAC system. These times are selected as the outside temperature and humidity change according to the time of the day. Each test takes a series of 10 readings with an interval of 5 minutes between each reading. These readings are then averaged and checked for the optimal ranges. The results are shown in Table 2.

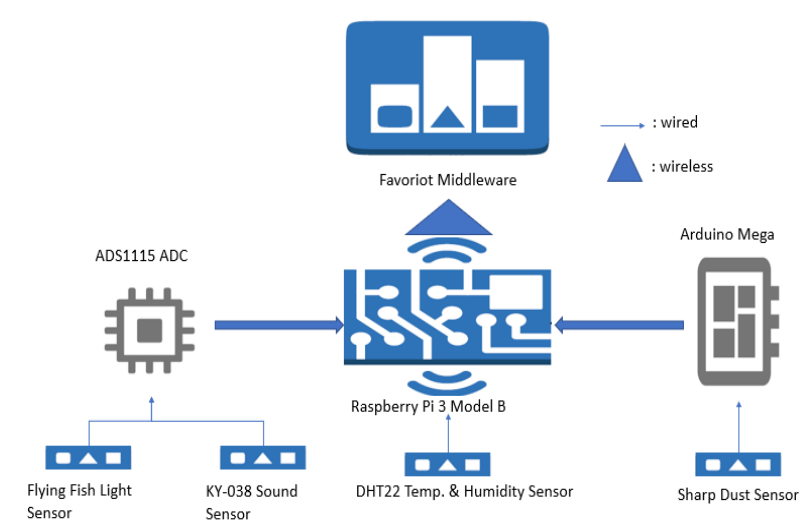

Figure 5. Block diagram for the SBS system

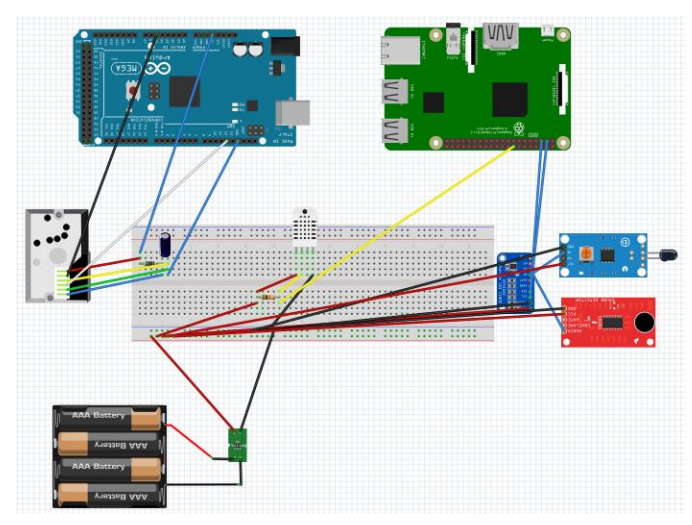

Figure 6. Wiring connections between the Raspberry Pi, Arduino and the sensors 
Table 1. Results for four different tests

\begin{tabular}{lcccc}
\hline & Test 1 & Test 2 & Test 3 & Test 4 \\
\hline Average temperatre $\left({ }^{\circ} \mathrm{C}\right)$ & 29.11 & 28.16 & 20.91 & 20.87 \\
Average humidity $(\mathrm{RH})$ & 88.24 & 90.21 & 68.54 & 69.44 \\
Average dust density $\left(\mathrm{mg} / \mathrm{m}^{3}\right)$ & 0.021 & 0.037 & 1.139 & 0.008 \\
Average luminousity $(\mathrm{mV})$ & 24685 & 1587 & 22277 & 2129 \\
Average noise $(\mathrm{mV})$ & 1426 & 1118 & 1420 & 809 \\
Probability HVAC malfunction & 0.667 & 0.667 & 0.667 & 0.333 \\
Probability of SBS & 0.6 & 0.6 & 0.6 & 0.6 \\
\hline
\end{tabular}

\subsection{Test 1 - Evening (3:30 pm), without HVAC system}

This test was conducted with the windows and door open to allow natural ventilation to take place. The average temperature is maintained with a slight increase in the average humidity due to the rainy weather. As for the average dust density, the values are well below the optimal level of $0.1 \mathrm{mg} / \mathrm{m}^{3}$. However, the light intensity was observed to be less than the optimal range due to the sensor's sensitivity. The Flying Fish light sensor is more sensitive towards natural light than artificial light. High SBS Probability and the HVAC system's malfunction was observed.

\subsection{Test 2 - Morning (9:30 a.m.), without HVAC system}

The second test conducted was at 9:30 am. Since it was also a rainy day, it affects both the average temperature and humidity readings. The average light luminosity has a significant difference. The sensor tested to be more sensitive to natural light with the average value here of $1587 \mathrm{mV}$, as compared to $24000 \mathrm{mV}$ in Test 1. The remaining two other parameters, noise and dust levels were recorded to be in the optimal ranges.

\subsection{Test 3 - Evening (3:30 pm), with HVAC}

Similar to the tests done without HVAC, two sets of tests were conducted at around the same time. However, this study area is equipped with a complete HVAC system capable of in-building environment regulation. The first test conducted was at $3: 30 \mathrm{pm}$ and the data shows significant difference in having a HVAC system, especially on temperature and humidity. The average temperature here is within the optimal levels, and the humidity was just slightly above the upper optimal of $65 \% \mathrm{RH}$. The dust density presented quite a high value due to a hardware glitch, a few readings were recorded to be at $0.08 \mathrm{mg} / \mathrm{m}^{3}$. This is just $0.02 \mathrm{mg} / \mathrm{m}^{3}$ lesser than the optimal limit. Such high dust densities are due to the carpeted flooring that collects more dust and gets dispersed by students walking around the vicinity.

\subsection{Test 4 - Morning (9:30 am), with HVAC}

This final test is conducted when the study area was just opened that morning, thus there were less occupants. Hence, the noise levels are below the optimal ranges. Interestingly, the dust density is relatively low. With not many students there at that time, there is lower dusts being dispersed into the air. The average humidity is observed to be reducing, the moment the air conditioning system is turned, compared to the increase in the humidity for the second once the air conditioning system is turned off. The light intensity was still below the optimal levels.

\section{CONCLUSION}

SBS is a syndrome that causes temporary symptoms such as fatigue, itchy eyes, skin rashes and nasal allergy which subside after the occupant is out of the building. In this paper, a simple, mobile and cost efficient Internet of Things (IoT) based SBS system has been proposed. The system is built using Raspberry Pi minicomputer equipped with temperature, humidity, light, sound and dust sensors that would then be integrated with an IoT middleware. Three IoT middleware are used to evaluate which one works best for the SBS system proposed. The combination of recorded sensor data would then be used to determine whether or not the building is causing SBS to the occupant. The studies show that FavorIoT platform is the most suitable IoT platform to be used with the SBS system and the system has successfully identified whether or not a building is causing SBS.

\section{ACKNOWLEDGEMENTS}

This work is supported by Tenaga Nasional Berhad under Seed Fund U-TI-RD-17-07 and Universiti Tenaga Nasional under UNIIG grant J510050782. 


\section{REFERENCES}

[1] Aditama TY. Sick Building Syndrome. Medical Journal of Indonesia. 2002; 11(2): 124-131.

[2] Guiseppe RP. Sick Building Syndrome: An overview to raise awareness. Journal of Building Appraisal. 2009; 5(1): 55-66.

[3] Joshi SM. The Sick Building Syndrome. Indian Journal of Occupational and Environmental Medicine. 2008; 12(2): 61-64.

[4] Ake T. Could an integrated biopsychosocial perspective prevent chronicity - Study of a Sick Building. European Journal of Public Health. 2000; 10(2): 133-137.

[5] Yan D, O’Brien W, Hong T, Feng X, Gunay HB, Tahmasebi F, Mahdavi A. Occupant behavior modeling for building performance simulation: Current state and future challenges. Energy and Buildings. 2015; 107: 264-278.

[6] He R, Gonzalez H. Comfort-Aware Building Climate Control Using Distributed-Parameter Models. arXiv preprint arXiv. 2017.

[7] Chua SJL, Ali AS, Lim MEL. Physical environment comfort impacts on office employee's performance. MATEC Web of Conferences, 2016; 66: 00124.

[8] Song W, Wang F, and Wei F. Hybrid cooling clothing to improve thermal comfort of office workers in a hot indoor environment. Building and Environment, 2016; 100: 92-101.

[9] Lee KY, Ho LY, Tan KH, Tham YY, Ling SP, Qureshi AM, Ponnudurai T. and Nordin R. Environmental and Occupational Health Impact of Bauxite Mining in Malaysia: A Review. International Medical Journal Malaysia, 2017; 16(2).

[10] Carletti C, Cellai G, Pierangioli L, Sciurpi F, and Secchi S. The influence of daylighting in buildings with parameters nZEB: application to the case study for an office in Tuscany Mediterranean area. Energy Procedia. 2017; 140: $339-350$

[11] Fink DJ, What is a safe noise level for the public? Am J Publ Health. 2017; 107(1): 44-45. 